\title{
Anti-obesity activity of hen egg anti-lipase immunoglobulin yolk, a novel pancreatic lipase inhibitor
}

Mai Hirose ${ }^{1}$,Taishi Ando ${ }^{1}$, Rahman Shofiqur ${ }^{2}$, Kouji Umeda², Yoshikatsu Kodama², Sa Van Nguyen², Tsuyoshi Goto ${ }^{1}$, Masaya Shimada ${ }^{1}$ and Satoshi Nagaoka ${ }^{1^{*}}$

\begin{abstract}
Background: There is completely no report about both hen egg anti-lipase immunoglobulin yolk (IgY) and its anti-obesity action. Thus, we tried to isolate and characterize a novel anti-lipase immunoglobulin from hen egg yolk. Moreover, we investigated whether hen egg yolk anti-lipase lgY inhibits pancreatic lipase activity in vitro, and examined its ability to prevent obesity in a murine high fat diet-induced obesity model.

Methods: We determined the inhibitory action of Anti-lipase lgY on lipase activity in vitro. We also focused our evaluation on the anti-obesity properties of Anti-lipase lgY in a murine high fat diet-induced obesity model.

Results: Anti-lipase IgY blocked porcine lipase activity with an $\mathrm{IC}_{50}$ of $0.49 \mu \mathrm{M}$. Supplementing the high fat diet with only $0.2 \%(\mathrm{w} / \mathrm{W})$ of Anti-lipase IgY for 35 days significantly decreased the weights of intraperitoneal adipose tissues, epididymal, mesenteric, retroperitoneal and perirenal adipose tissues, and the amounts of hepatic total lipid, triglyceride, and cholesterol. This was accompanied by a significant increase in the fecal excretion of triglyceride in the absence of diarrhea. Furthermore, Anti-lipase IgY treatment restored body weight gain to levels similar to mice fed with Control IgY.

Conclusions: This study provides the first report of the development of anti-lipase $\lg Y$ and the direct evidence that inhibition of pancreatic lipase using Anti-lipase $\lg \mathrm{Y}$ is an effective anti-obesity treatment due to the associated increase in fecal excretion of triglyceride.
\end{abstract}

Keywords: Obesity, IgY, Pancreatic lipase, Lipid, Mice

\section{Finding}

Introduction

Obesity causes excess fat accumulation in several tissues in addition to white adipose tissue (WAT), such as other insulin-responsive organs including the skeletal muscle and liver; this predisposes individuals to the development of insulin resistance. Obesity is strongly associated with metabolic syndrome, which is characterized by the presence of insulin resistance, hypertension, and hyperlipidemia. Metabolic syndrome, which is closely linked to atherosclerosis, has become a major public health problem.

\footnotetext{
* Correspondence: nagaoka@gifu-u.ac.jp

'Department of Applied Life Science, Faculty of Applied Biological Sciences, Gifu University, 1-1 Yanagido, Gifu 501-1193, Japan

Full list of author information is available at the end of the article
}

Several approaches for prevention and treatment of obesity have been reported [1]. Among these, both natural and synthetic pancreatic lipase inhibitors are effective in obesity prevention, likely due to their inhibition of intestinal lipid absorption. Indeed, a specific pancreatic inhibitor, Orlistat, has been used in the clinic for the prevention of obesity [2]. In animal studies, a major tea catechin, (-)-epigallocatechin-3-gallate [3] and polyphenol extracts in black tea [4] prevented high-fat dietinduced obesity via the inhibition of pancreatic lipase.

Another innovative candidate approach for pancreatic lipase inhibition is oral administration of anti-lipase immunoglobulin yolk (IgY) antibodies. There is completely no report about both hen egg yolk anti-lipase IgY and its anti-obesity action. Hens transfer immunoglobulin G (IgG) in blood into the egg yolk to provide acquired 
immunity to the offspring; this transferred IgG is termed IgY. The IgY technology offers several advantages over other methods of antibody production. For example, development and production of specific IgY can be achieved through collecting eggs from hens immunized with the target antigen, without the need for painful blood sampling and sacrifice of the animals.

The stability of $\operatorname{IgY}$ in pressure, heat, $\mathrm{pH}$, trypsin, chymotrypsin, pepsin, and in the gastrointestinal tract has been well-documented [5]. IgY is relatively stable to pressure up to $4,000 \mathrm{~kg}$ per $\mathrm{cm}^{2}$. IgY is stable at temperature ranging between $30^{\circ} \mathrm{C}$ and $70^{\circ} \mathrm{C}$. It was found that the activity range of $\mathrm{IgY}$ for $\mathrm{pH}$ was $\mathrm{pH} 3.5 \sim 11$. The stability of IgY at $\mathrm{pH} 3$ was increased in the presence of sorbitol [6]. IgY is quite resistant against trypsin and chymotrypsin inactivation, but degraded by pepsin [7]. Moreover, our group has investigated the in vivo passage and the efficacy of IgY in the gastrointestinal tract of piglets and calves. Our results indicated that IgY powder was transported as immunologically functional molecules from the stomach down to the small intestine of calves while retaining much of their original biological activity [8].

Exploiting the peculiarities of the avian immune system, it is possible to mass-produce specific IgY antibody against various antigens, since IgY levels are extremely high in egg yolk, and one hen lays 250-300 eggs per year. Indeed, other scientists as well as we have produced IgY antibodies against microorganisms such as cholera [9] and Candida [10] using this method. Furthermore, we have shown that oral passive immunization with $\operatorname{IgY}$ antibodies prevented and improved antigen-induced disease symptoms in animal studies $[11,12]$.

Here, we describe the production of a novel anti-lipase specific IgY from egg yolk following immunization of hens with a porcine pancreatic lipase, a key enzyme required for lipid digestion. Since the oral passive IgYbased immunotherapeutic strategy outlined above was effective against bacteria, we predicted that our new approach would produce a selective inhibitor of pancreatic lipase activity. By extension, we hypothesized that this inhibitor may exert anti-obesity effects. Thus, in this study, we investigated whether hen egg yolk anti-lipase IgY inhibits pancreatic lipase activity in vitro, and examined its ability to prevent obesity in a murine high fat diet-induced obesity model.

\section{Methods and procedures Reagents}

The enzyme substrates and reagents were as follows: triolein, taurocholate, colipase, and L- $\alpha$-phosphatidylcholine were from Sigma (MO, USA). High pure porcine pancreatic lipase was obtained from Elastin Products Co (Owensville, MO, USA). The fresh porcine pancreas was obtained from the local slaughtering house in Gifu, Japan. Lipase purification procedure was based upon the method of Garner and Smith [13]. Anti-porcine pancreas lipasespecific IgY containing preparation (designated as Antilipase IgY) and control IgY preparation (designated as Control IgY) were kindly provided by EW Nutrition Japan. (Gifu, Japan).

\section{Anti-Lipase IgY preparation}

Five-month-old White leghorn hens (Hyline W36; Japan Layer, Gifu) were immunized according to the method described by Yokoyama et al. [14]. Briefly, the vaccine was prepared by mixing $0.5 \mathrm{mg}$ of purified lipase antigen with $0.5 \mathrm{ml}$ emulsion oil containing 5\% Arlacel 80 (Maine Biological Laboratories, Waterville, Me, USA) and hens were immunized by injecting $0.5 \mathrm{ml}$ to each of the breast muscles. Six weeks after the initial immunization, a booster was given in the same manner. Eggs from the immunized hens were harvested daily and stocked at $4^{\circ} \mathrm{C}$. Egg yolk was separated carefully from the albumin. The yolk was then pooled, homogenized, and filtrated. Partially purified specific IgY powder was prepared by ammonium sulfate precipitation [15], and freeze-dry. Control IgY powder was prepared from the egg of non-immunized hens by the same method.

\section{Assay to determine titer of anti-lipase specific $\lg Y$}

The concentrations of both Anti-lipase IgY and Control IgY were determined using an enzyme-linked immunosorbent assay (ELISA) method as previously described [16].

\section{Lipase activity assay}

The porcine pancreatic lipase activity was determined using the method of Tsujita et al. [17].

\section{Animals and diets}

Male 6-week-old C57BL/6 J mice were purchased from Japan SLC (Hamamatsu, Japan). Mice were housed individually in standard plastic rodent cages, and placed in a room where the temperature was maintained at $22 \pm 2.0^{\circ} \mathrm{C}$ with a 12-h light:dark cycle (lights on 0800-2000 h). All the mice consumed a commercial nonpurified MF (Mouse Flat) diet (Oriental, Yeast, Osaka, Japan) and tap water ad libitum for 4 days prior to their division into the following two weight-matched groups $(\mathrm{n}=8: 8$ mice per group): $0.2 \%(\mathrm{w} / \mathrm{w})$ Control IgY-supplemented $\operatorname{diet}(\mathrm{CY})$ group, and $0.2 \%(\mathrm{w} / \mathrm{w})$ Anti-lipase IgY-supplemented (AY) group. The compositions of the experimental diets are shown in Table 1. Mice were fed on these diets for 35 days. To determine the effective dose of Anti-lipase IgY in mice, we have done the preliminary experiment for 8 days. After this preliminary experiment, we have chosen $0.2 \%(\mathrm{w} / \mathrm{w})$ of IgY in mouse study. 
Table 1 Composition of experimental diets

\begin{tabular}{lcr}
\hline Components & CY & AY \\
\hline & g/kg & \\
Casein & 286 & 286 \\
Control lgY & 2 & - \\
Anti-lipase IgY & - & 2 \\
Corn starch & 172 & 172 \\
Sucrose & 86 & 86 \\
Cellulose & 65 & 65 \\
Soybean oil & 40 & 40 \\
Lard $_{\text {Mineral }}^{1}$ & 300 & 300 \\
Vitamine $^{2}$ & 35 & 35 \\
Choline chloride $^{\text {All }}$ & 10 & 10 \\
\hline
\end{tabular}

${ }^{1}$ AIN-93G Mineral mixture.

${ }^{2}$ AIN-93G vitamin mixture.

Food intake and body weights of the mice were recorded daily during the feeding period. At the end of the experimental period, animals were anesthetized with ether after a 22-h fasting period. Livers and visceral fat pads were removed and weighed. The plasma, liver, and visceral fat pad samples were collected and stored at $-80^{\circ} \mathrm{C}$ until analysis. Fecal collections (d 7-9) were used for determining fecal lipids. The care and experimental procedures were approved by the Animal Care and Use Committee of Gifu University.

\section{Biochemical analyses}

Various lipid concentrations were determined using commercially available kits as follows: plasma, liver, and fecal triglyceride with Triglyceride E-test Wako (Wako Pure Chemical, Osaka, Japan) and plasma, liver, and fecal cholesterol with Cholesterol E-test Wako (Wako Pure Chemical, Osaka, Japan). Liver and fecal lipids were extracted by the method of Folch et al. [18], and total lipids were determined gravimetrically by the method of Nagaoka et al. [19].

Plasma glucose levels were determined by the glucose CII test (Wako Pure Chemical, Osaka, Japan). Plasma insulin levels were measured with an ELISA kit (Morinaga Institute of Biological Science, Yokohama, Japan). Plasma TNF- $\alpha$ levels were measured with an ELISA kit (R\&D Systems, Minneapolis, USA).

\section{Statistical analyses}

All data presented in this study were normally distributed. Data were tested for normal distribution by the Kolmogorov-Smirnov normality test [20,21]. After Kolmogorov-Smirnov test, the statistical significance of differences was evaluated using the Student's t-test [22].

\section{Results}

Titer of anti-lipase specific $\lg Y$

The titers of Anti-lipase IgY (AY) or Control IgY (CY) used for the mouse study were $25.72 \pm 1.37 \mathrm{mg} / \mathrm{g}$ or $0 \mathrm{mg} / \mathrm{g}$ preparation, respectively.

\section{Inhibitory effect on lipase activity}

AY inhibited pancreatic lipase activity by $95.4 \sim 18.3 \%$ at concentrations between $10,000 \sim 10 \mu \mathrm{g} / \mathrm{ml}$, whereas $\mathrm{CY}$ did not inhibit triolein hydrolysis by pancreatic lipase. The $\mathrm{IC}_{50}$ value of $\mathrm{AY}$ was $88 \mu \mathrm{g} / \mathrm{ml}(0.49 \mu \mathrm{M})$. Growth inhibition of pancreatic lipase occurred in a doseresponsive manner (Figure 1).

Body weights, total food intake, fecal and tissue weights Initial body weight, final body weight, body weight gains, total food intake, fecal and liver weights were all unaffected by dietary treatment (Table 2). The adipose tissue (epididymal, mesenteric, retroperitoneal and perirenal) weight was significantly lower in the AY group than that of the CY group.

\section{Plasma parameters, liver and fecal lipids}

The plasma triglyceride tended to be lower $(\mathrm{p}=0.093)$ in the AY group than that of the CY group (Table 2).

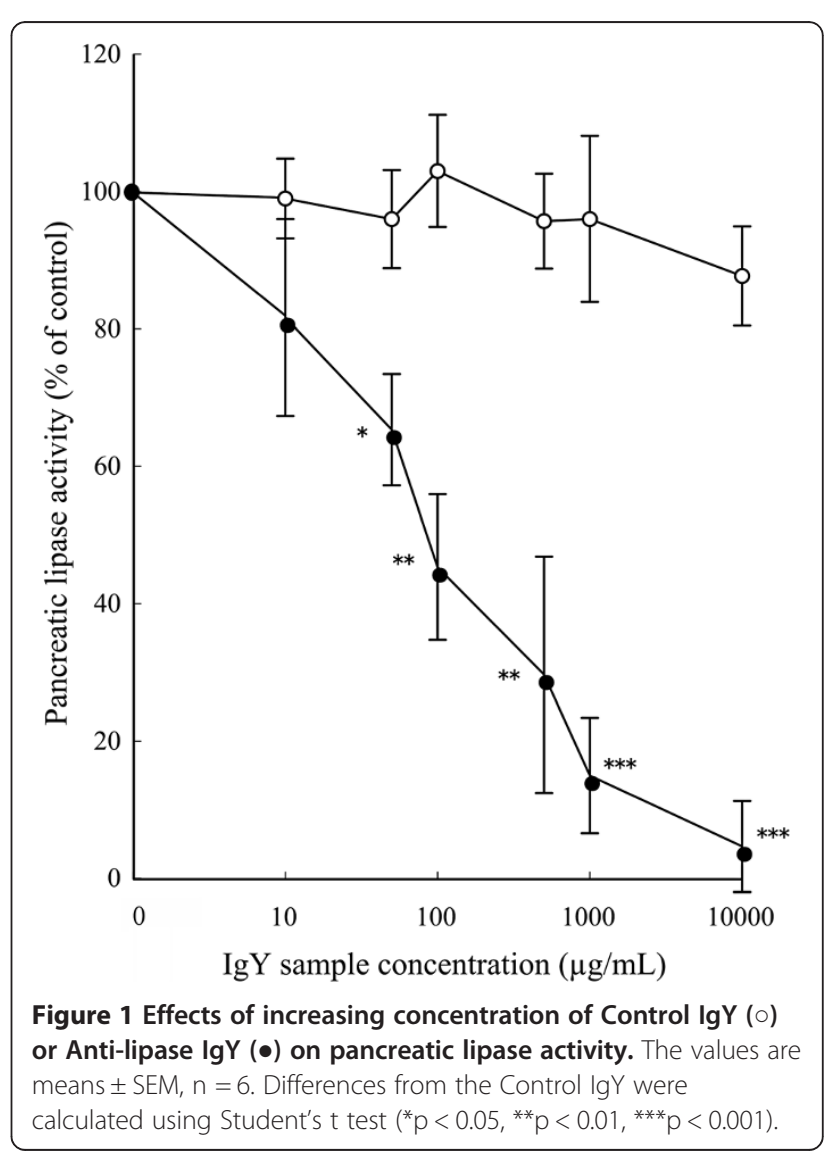


Table 2 Effects of Control IgY (CY) and Anti-lipase IgY (AY) on physiological parameters

\begin{tabular}{|c|c|c|}
\hline & $\mathrm{CY}$ & AY \\
\hline Initial body weight (g) & $27.57 \pm 0.27$ & $22.50 \pm 0.38$ \\
\hline Final body weight (g) & $26.18 \pm 0.75$ & $25.47 \pm 1.01$ \\
\hline Body weight gain ( $g / 35 \mathrm{~d}$ ) & $3.61 \pm 0.88$ & $2.97 \pm 0.85$ \\
\hline Total food intake (g/35 d) & $99.27 \pm 4.81$ & $95.28 \pm 2.31$ \\
\hline Fecal dry weight (g/3d) & $0.96 \pm 0.03$ & $0.91 \pm 0.02$ \\
\hline \multicolumn{3}{|l|}{ Tissue weight (mg/g B.W.) } \\
\hline Liver weight & $33.6 \pm 0.64$ & $34.7 \pm 1.07$ \\
\hline Epididymal WAT & $26.8 \pm 2.76$ & $20.2 \pm 0.40^{*}$ \\
\hline Mesenteric WAT & $9.32 \pm 0.94$ & $6.57 \pm 0.50^{*}$ \\
\hline Retroperitoneal WAT & $14.0 \pm 1.18$ & $10.8 \pm 0.41^{*}$ \\
\hline Perirenal WAT & $9.51 \pm 1.31$ & $6.32 \pm 0.40^{*}$ \\
\hline Intraperitoneal WAT & $59.6 \pm 5.74$ & $43.9 \pm 0.73^{*}$ \\
\hline \multicolumn{3}{|l|}{ Tissue weight (mg) } \\
\hline Liver weight & $877.5 \pm 22.6$ & $877.6 \pm 20.5$ \\
\hline Epididymal WAT & $709.9 \pm 87.3$ & $513.5 \pm 20.4^{*}$ \\
\hline Mesenteric WAT & $246.5 \pm 29.9$ & $169.0 \pm 16.4^{*}$ \\
\hline Retroperitoneal WAT & $332.0 \pm 53.1$ & $273.3 \pm 13.0^{*}$ \\
\hline Perirenal WAT & $251.6 \pm 39.9$ & $162.0 \pm 13.5^{*}$ \\
\hline Intraperitoneal WAT & $1573.4 \pm 180.5$ & $1117.8 \pm 52.0^{*}$ \\
\hline \multicolumn{3}{|l|}{ Plasma parameters } \\
\hline Triglyceride (mg/dl) & $54.2 \pm 3.6$ & $44.6 \pm 3.9$ \\
\hline Cholesterol (mg/dl) & $109.1 \pm 3.9$ & $104.6 \pm 3.4$ \\
\hline Glucose (mg/dl) & $134.7 \pm 7.1$ & $137.1 \pm 7.2$ \\
\hline Insulin (ng/ml) & $0.14 \pm 0.02$ & $0.14 \pm 0.02$ \\
\hline TNF-a (pg/ml) & $3.29 \pm 0.12$ & $3.66 \pm 0.17$ \\
\hline \multicolumn{3}{|l|}{ Liver lipids (mg/g liver) } \\
\hline Total lipids & $132.6 \pm 10.8$ & $90.6 \pm 7.9^{* *}$ \\
\hline Triglyceride & $51.9 \pm 0.9$ & $45.0 \pm 2.6^{*}$ \\
\hline Cholesterol & $6.77 \pm 0.45$ & $4.32 \pm 0.17^{* *}$ \\
\hline \multicolumn{3}{|l|}{ Fecal lipids (mg/3d) } \\
\hline Total lipids & $71.4 \pm 2.89$ & $77.1 \pm 2.48$ \\
\hline Triglyceride & $5.67 \pm 0.32$ & $7.50 \pm 0.64^{*}$ \\
\hline Cholesterol & $6.65 \pm 0.35$ & $6.72 \pm 0.26$ \\
\hline
\end{tabular}

1. Each value is the mean $\pm S E M, n=8$.

2. Asterisks indicate significant differences as compared with mice fed a

high-fat diet containing control IgY by Student's t-test ( $\left.{ }^{*} p<0.05 ;{ }^{* *} p<0.01\right)$.

Liver triglyceride and cholesterol were significantly lower in the AY group than in the CY group. The fecal excretion of triglyceride was significantly higher in the AYtreated animals when compared with controls. Plasma glucose, insulin and TNF- $\alpha$ levels were not significantly changed between AY group and CY group.

\section{Discussion}

To begin the search for alternative anti-obesity agents, we exploited a hen immunization model to produce
Anti-lipase IgY, a novel antibody that recognizes porcine pancreatic lipase. The lipolytic activity was strongly inhibited in a concentration-dependent manner upon addition of Anti-lipase IgY when compared with Control IgY (Figure 1). These results suggest that Anti-lipase IgY reacts specifically with pancreatic lipase. Surprisingly, the $\mathrm{IC}_{50}$ of Anti-lipase IgY $(0.49 \mu \mathrm{M})$ that elicits an antiobesity effect is approximately half that of Orlistat, which has an $\mathrm{IC}_{50}$ of $0.96 \mu \mathrm{M}$ [17]. Both of these treatments are in turn superior to the green tea polyphenol, (-)-epigallocatechin gallate (EGCG), which has an $\mathrm{IC}_{50}$ of $7.5 \mu \mathrm{M}$ [3] accompanying an anti-obesity action in mice fed a high fat diet. Interestingly, as the effective dose of IgY is $0.2 \%$ $(w / w)$ in animal study, it is the lowest value among functional food components such as EGCG [3,4].

Recently, the availability of lipase inhibitor agent for preventing metabolic syndrome has received much attention. Orlistat, an anti-obesity drug used in the clinic, is a potent and specific covalent inhibitor of digestive lipase $[2,23]$, which leads to reduced intestinal absorption of lipolysis products. However, the use of Orlistat is frequently associated with gastrointestinal adverse effects, such as oily stools, diarrhea, cholelithiasis and cholestatic hepatitis $[2,24]$. But, judging from our observation and the data of liver lipids analysis, there is no side effect by the treatment of anti-lipase IgY as observed by Orlistat.

The effects of Anti-lipase IgY and Control IgY on obesity were evaluated in mice fed a high-fat diet containing $0.2 \%(\mathrm{w} / \mathrm{w})$ IgY, respectively. Anti-lipase IgY supplementation significantly decreased adipose tissue weights and hepatic lipid levels and also significantly increased the fecal excretion of triglyceride compared with Control IgY feeding (Table 2). These results suggest an anti-obesity function of Anti-lipase IgY: it inhibits the hydrolysis of dietary fat in the small intestine and reduces intestinal absorption of dietary fat, which is then excreted into the feces.

To investigate the effect of anti-lipase IgY on the absorption of triglyceride in the diet, we analyzed fecal lipids contents. Previous study showed that lipase inhibition by synthetic lipase inhibitor Orlistat was extremely fast (half-inhibition time $<1 \mathrm{~min}$ ) [25]. Moreover, in our preliminary study, single anti-lipase IgY administration tended to decrease in plasma triglyceride levels after single gavage of olive oil. These results indicate that the treatment with anti-lipase IgY for short term is effective for the increase in fecal triglyceride content. Thus, we performed fecal collection during day 7 through 9. On the other hand, it seemed to need longer time before the treatment with anti-lipase IgY become effective against the other measurements, such as adiposity and hepatic lipid accumulation. Thus, in this study, we investigated the effects of anti-lipase IgY treatment for longer period 
(35 days) on these parameters. Unfortunately, we have no data about a timing effect on fecal lipid excretion, and further investigation on it is important in future study. However, to our knowledge, there is no report about the tolerant to pancreatic lipase inhibitor, such as Orlistat. Moreover, Moreno et al. reported that dietary supplementation with peanuts shell extracts, which inhibit pancreatic lipase, significantly increased the excretion of fecal lipids in rats fed a high fat diet at 3 weeks of the study and the increase continued until the end of the study, 12 weeks [26]. In addition, Desmarchelier et al. reported that feeding mice a high fat Western diet containing cholesterol remarkably increased the excretion of fecal neutral sterol during day 4-11 of the experiment and the increase was kept until late in the experiments, day 74-81 [27]. These findings in the literatures suggest that diet-, nutrient- and food ingredientstimulated enhancement of fecal lipid excretion observed in early experimental stage could be sustained even in late stage. Therefore, we determined fecal lipids during the relatively early stage and found a significant increase in the fecal triglyceride of mice treated with anti-lipase IgY, which is predicted to be kept until the late stage.

The aim of this study is to determine whether the anti-lipase IgY has the preventive effects on early obesity development. Obesity is defined as excessive fat accumulation [28]. Thus, in this study, we mainly investigated the effects of relatively short term treatment (35 days) with the anti-lipase IgY on the high-fat diet-induced development of white adipose tissues (WAT). Although the treatment with anti-lipase IgY didn't affect body weight (tended to decrease but not significantly), we demonstrated that the anti-lipase IgY inhibited visceral WAT accumulation, and we evaluated that the antilipase IgY has an anti-obesity effect. A similar claim was made in the study done by Foucault AS et al. [29]. The reason why anti-lipase IgY didn't affect body weight gain in this study may be due to the experimental period because circular triglyceride level in mice fed control HFD in this study is not higher than those in mice fed HFD for prolonged period in previous studies [30,31]. Therefore, further investigation is needed about the effects of anti-lipase IgY treatment for longer period on the body weight gain and obesity-induced metabolic disorders, in future. However, a specific pancreatic lipase inhibitor, Orlistat, has been used in clinics for the prevention of obesity [2], and Orlistat has been shown not only to prevent body weight gain but also to improve obesityinduced metabolic disorders, such as glucose intolerance and diabetes [32]. Our results showed that anti-lipase IgY has more potent inhibitory effect on the pancreatic lipase than Orlistat (IC50 values: $0.49 \mu \mathrm{M}$ vs $0.96 \mu \mathrm{M}$ ) [17]. Thus, we think we can expect that anti-lipase IgY has useful effect on body weight gain and obesityinduced metabolic disorders in the prolonged treatment.

Taken all together, the data from our study show that Anti-lipase IgY is a promising new lead biologic agent for the development of functional foods and medicines expected to prevent and improve obesity.

\section{Competing interests}

The authors declare that they have no competing interests.

\section{Authors' contributions}

Contribution of each author: $\mathrm{S} \mathrm{N}$ designed the research and wrote the manuscript; $\mathrm{M} \mathrm{H}$ conducted the research and wrote the manuscript; T A, R S and $\mathrm{K} U$ conducted the research; Y K, SV N, T G and M S analyzed the data. All authors read and approved the final manuscript.

\section{Acknowledgements}

This work was supported in part by grants from the Seeds Validation Exploratory Research of Japan Science and Technology Agency.

\section{Author details}

${ }^{1}$ Department of Applied Life Science, Faculty of Applied Biological Sciences, Gifu University, 1-1 Yanagido, Gifu 501-1193, Japan. ${ }^{2}$ Immunology Research Institute in Gifu, EW Nutrition Japan, Gifu, Japan.

Received: 11 September 2013 Accepted: 2 December 2013

Published: 9 December 2013

\section{References}

1. Birari RB, Bhutani KK: Pancreatic lipase inhibitors from natural sources: unexplored potential. Drug Discov Today 2007, 12:879-889.

2. Ballinger A, Peikin SR: Orlistat: its current status as an anti-obesity drug. Eur J Pharmacol 2002, 440:109-117.

3. Grove KA, Sae-tan S, Kennett MJ, Lambert JD: (-)-Epigallocatechin-3-gallate inhibits pancreatic lipase and reduces body weight gain in high fat-fed obese mice. Obesity 2012, 20:2311-2313.

4. Uchiyama S, Taniguchi Y, Saka A, Yoshida A, Yajima H: Prevention of diet-induced obesity by dietary black tea polyphenols extract in vitro and in vivo. Nutrition 2011, 27:287-292.

5. Shin JH, Yang M, Nam SW, Kim JT, Myung NH, Bang WG, Roe $H_{\mathrm{H}}$ : Use of egg yolk-derived immunoglobulin as an alternative to antibiotic treatment for control of Helicobacter pylori Infection. Clin Diagn Lab Immunol 2002, 9:1061-1066.

6. Lee KA Chang SK, Lee YJ, Lee JH, Koo NS: Acid stability of anti-Helicobacter pyroli lgY in aqueous polyol solution. J Biochem Mol Biol 2002, 35:488-493.

7. Hatta H, Tsuda K, Akachi S, Kim M, Yamamoto T, Ebina T: Oral passive immunization effect of anti-human rotavirus $\lg Y$ and its behavior against proteolytic enzymes. Biosci Biotechnol Biochem 1993, 57:1077-1081.

8. Rahman S, Nguyen SV, Icatlo FC Jr, Umeda K, Kodama Y: Oral passive IgY-based immunotherapeutics: a novel solution for prevention and treatment of alimentary tract diseases. Hum Vaccin Immunother 2013, 14:1039-1048

9. Hirai K, Arimitsu H, Umeda K, Yokota K, Shen L, Ayada K, Kodama Y, Tsuji T, Hirai Y, Oguma K: Passive oral immunization by egg yolk immunoglobulin (IgY) to Vibrio cholerae effectively prevents cholera. Acta Med Okayama 2010, 64:163-170.

10. Ibrahim ESM, Rahman AK, Isoda R, Umeda K, Nguyen SV, Kodama Y: In vitro and in vivo effectiveness of egg yolk antibody against Candida albicans (anti-CA lgY). Vaccine 2008, 26:2073-2080.

11. Neri P, Tokoro S, Kobayashi R, Sugiyama T, Umeda K, Shimizu T, Tsuji T, Kodama Y, Oguma K, Mori H: Specific egg yolk immunoglobulin as a new preventive approach for Shiga-toxin-mediated diseases. PLOS ONE 2011, 6:e26526.

12. Rahman S, Higo MK, Htunc KW, Taniguchi K, Icatlo FC, Tsuji T, Kodama Y, Nguyen SV, Umeda K, Oo HN, Myint YY, Htut T, Myint SS, Thura K, Thu HM, Fatmawati NND, Oguma K: Randomized placebo-controlled clinical trial of immunoglobulin $Y$ as adjunct to standard supportive therapy for rotavirus-associated diarrhea among pediatric patients. Vaccine 2012, 30:4661-4669 
13. Garner CW, Smith LC: Porcine pancreatic lipase. A glycoprotein. J Biol Chem 1972, 247:561-565.

14. Yokoyama H, Hashi T, Umeda K, Icatlo FC Jr, Kuroki M, Ikemori Y, Kodama Y: Effect of oral egg antibody in experimental F18+ Escherichia coli infection in weaned pigs. J Vet Med Sci 1997, 59:917-921.

15. Kuroki M, Ikemori Y, Yokoyama H, Peralta RC, Icatlo FC, Kodama Y: Passive protection against bovine rotavirus-induced diarrhea in murine model by specific immunoglobulins from chicken egg yolk. Vet Microbiol 1993, 37:135-146.

16. Icatlo FC, Kuroki M, Kobayashi C, Yokoyama H, Ikemori Y, Hashi T, Kodama Y: Affinity purification of Helicobacter pylori urease. Relevance to gastric mucin adherence by urease protein. J Biol Chem 1998, 273:18130-18138.

17. Tsujita T, Takaichi H, Takaku T, Aoyama S, Hiraki J: Antiobesity action of epsilon-polylysine, a potent inhibitor of pancreatic lipase. J Lipid Res 2006, 47:1852-1858.

18. Folch J, Lees M, Sloane Stanley GH: A simple method for the isolation and purification of total lipids from animal tissues. J Biol Chem 1957, 226:497-509.

19. Nagaoka S, Miwa K, Eto M, Kuzuya Y, Hori G, Yamamoto K: Soy protein peptic hydrolysate with bound phospholipids decrease micellar solubility and cholesterol absorption in rats and Caco-2 cells. J Nutr 1999, 129:1725-1730.

20. Ong LD, LeClare PC: The Kolmogorov-Smirnov test for the log-normality of sample cumulative frequency distributions. Health Phys 1968, 14:376.

21. Rosenthal R: An application of the Kolmogorov-Smirnov test for normality with estimated mean and variance. Psychol Rep 1968, 22:570.

22. Snedecor GW, Cochran WG: Statistical methods. In Ames, Japanese Edition: Iwanami Pub. Inc. 6th edition. Tokyo: The lowa State University Press; 1967.

23. Luthi-Peng $Q$, Märki HP, Hadváry P: Identification of the active-site serine in human pancreatic lipase by chemical modification with tetrahydrolipstatin. FEBS Lett 1992, 299:111-115.

24. Filippatos TD, Derdemezis CS, Gazi IF, Nakou ES, Mikhailidis DP, Elisaf MS: Orlistat-associated adverse effects and drug interactions a critical review. Drug Saf 2008, 31:53-65.

25. Carrière F, Renou C, Ransac S, Lopez V, de Caro J, Ferrato F, de Caro A, Fleury A, Sanwald DP, Lengsfeld H, Beglinger C, Hadvary P, Verger R, Laugier $R$ : Inhibition of gastrointestinal lipolysis by Orlistat during digestion of test meals in healthy volunteers. Am J Physiol Gastrointest Liver Physiol 2001, 281:G16-G28.

26. Moreno DA, llic N, Poulev A, Raskin I: Effects of Arachis hypogaea nutshell extract on lipid metabolic enzymes and obesity parameters. Life Sci 2006, 78:2797-2803.

27. Desmarchelier C, Dahlhoff C, Keller S, Sailer M, Jahreis G, Daniel H: C57BI/ $6 \mathrm{~N}$ mice on a western diet display reduced intestinal and hepatic cholesterol levels despite a plasma hypercholesterolemia. BMC Genomics 2012, 13:84.

28. Rueda-Clausen CF, Padwal RS, Sharma AM: New pharmacological approaches for obesity management. Nat Rev Endocrinol 2013, 9:467-478.

29. Foucault AS, Mathe V, Lafont R, Even P, Dioh W, Veillet S, Tome D, Huneau JF, Hermier D, Boulange AQ: Quinoa extract enriched in 20-hydroxyecdysone protects mice from diet-induced obesity and modulates adipokines expression. Obesity 2012, 20:270-277.

30. Ables GP, Perrone CE, Orentreich D, Orentreich N: Methionine-restricted C57BL/6 J mice are resistant to diet-induced obesity and insulin resistance but have low bone density. PLoS One 2012, 7:e51357.

31. Takasawa K, Kubota N, Terauchi Y, Kadowaki T: Impact of increased PPARY activity in adipocytes in vivo on adiposity, insulin sensitivity and the effects of rosiglitazone treatment. Endocr J 2008, 55:767-776.

32. Heymsfield SB, Segal KR, Hauptman J, Lucas CP, Boldrin MN, Rissanen A, Wilding JP, Sjöström L: Effects of weight loss with orlistat on glucose tolerance and progression to type 2 diabetes in obese adults. Arch Intern Med 2000, 160:1321-1326.

doi:10.1186/1743-7075-10-70

Cite this article as: Hirose et al: Anti-obesity activity of hen egg anti-lipase immunoglobulin yolk, a novel pancreatic lipase inhibitor. Nutrition \& Metabolism 2013 10:70.

\section{Submit your next manuscript to BioMed Central and take full advantage of:}

- Convenient online submission

- Thorough peer review

- No space constraints or color figure charges

- Immediate publication on acceptance

- Inclusion in PubMed, CAS, Scopus and Google Scholar

- Research which is freely available for redistribution

Submit your manuscript at www.biomedcentral.com/submit
() Biomed Central 